from continuous data, which has been shown to inflate drugplacebo differences. ${ }^{2}$ Network analysis is also likely to exaggerate differences, since the degree of improvement in comparative trials is higher than in placebo-controlled trials. ${ }^{3}$ The continuous data, which showed a standardised mean difference (SMD) of 0.3 , is in line with other meta-analyses in showing small and almost certainly clinically insignificant differences between antidepressants and placebo, equivalent to around two points difference on the Hamilton Rating Scale for Depression (HRSD) ${ }^{4,5}$

Jauhar and Young make a good point about the validity of the HRSD, but it is nevertheless used as the primary outcome of most trials. Analyses of the subjective mood item are thus more likely to be influenced by selective reporting of positive findings. However, they are wrong about the Medical Research Council trial, where the dose of imipramine was $200 \mathrm{mg}$ and that of phenelzine was $60 \mathrm{mg}$. There is indeed evidence either way on the association between severity and antidepressant response, but even in studies with positive findings, effect sizes in those with severe depression are small and unlikely to be clinically significant, and the association may be accounted for by differing expectations in people with more or less severe symptoms. ${ }^{6}$

I agree with the gist of Dr Dunleavy's response. Recommending antidepressants because they produce emotion-blunting effects, or other useful mental alterations (sedation with tricyclics, for example), is a drug-centred model of prescribing. I don't have a problem with this as long as the patient is properly informed that placebo-controlled trials suggest little if any superiority of antidepressants, that they have full knowledge of all the potential adverse effects, and that they are quite clear that the idea that antidepressants correct an underlying chemical imbalance is not supported by evidence. Then they can make their own informed decision.

Joanna Moncrieff, University College London; email: j.moncrieff@ucl.ac.uk

1 Moncrieff J. The Myth of the Chemical Cure: A Critique of Psychiatric Drug Treatment. Palgrave Macmillan, 2008.

2 Kirsch I, Moncrieff J. Clinical trials and the response rate illusion. Contemp Clin Trials 2007; 28: 348-51.

3 Sinyor $M$, Levitt AJ, Cheung AH, Schaffer A, Kiss A, Dowlati $Y$, et al. Does inclusion of a placebo arm influence response to active antidepressant treatment in randomized controlled trials? Results from pooled and meta-analyses. J Clin Psychiatry 2010; 71(3): 270-9.

4 Kirsch I, Moore TJ, Scoboria A, Nicholls SS. The emperor's new drugs: an analysis of antidepressant medication data submitted to the US Food and Drug Administration. Prevent Treat 2002; 5(1): 23.

5 Turner EH, Matthews AM, Linardatos E, Tell RA, Rosenthal R. Selective publication of antidepressant trials and its influence on apparent efficacy. N Engl J Med 2008; 358(3): 252-60.

6 Kirsch I, Deacon BJ, Huedo-Medina TB, Scoboria A, Moore TJ, Johnson BT. Initial severity and antidepressant benefits: a meta-analysis of data submitted to the Food and Drug Administration. PLoS Med 2008; 5(2): e45.

doi:10.1192/bjb.2018.34

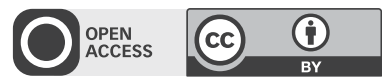

(c) The Author 2018. This is an Open Access article, distributed under the terms of the Creative Commons Attribution licence (http://creativecommons.org/ licenses/by/4.0/), which permits unrestricted re-use, distribution, and reproduction in any medium, provided the original work is properly cited.

\section{Unlocking an acute psychiatric ward: open doors, absent patients?}

In their recent paper, Beaglehole and colleagues ${ }^{1}$ reported on the effects of unlocking an acute psychiatric ward. Despite a $58 \%$ increase in unauthorised absences and an $8 \%$ increase in violent incidents, they concluded that a less restrictive environment had some positive effects, most notably a reduction in the total hours of seclusion per month.

Our service has recently undertaken a similar transition from a locked acute ward opened (and locked) in the 1930s, to an unlocked newly built unit opened in 2016. When comparing the 6 months before and after this transition, we too found that the rate of unauthorised absences increased by $100 \%$ from a mean of 4 to 8 per month. Unlike Beaglehole, however, we observed a decrease in rates of violent incidents by $27.4 \%$ (from a mean of 31.7 to 23 per month), and an increase in the total hours of seclusion per month by $213.4 \%$ (from a mean of 28.21 to 88.42 hours per month). Of note, admission rates increased from a mean of 20 to 23 per month during the same time period.

Although a reduction in the rate of violent incidents (and, in the case of Beaglehole, reduced levels of seclusion) strengthens the case for provision of care in unlocked settings, should we be concerned about the increased rate of unauthorised absences found in both studies?

The largest available study on this topic ${ }^{2}$ would suggest not. In their 15-year observational study involving 145,738 German in-patients, Huber et al concluded that locked doors do not prevent suicides, or indeed unauthorised absences.

Although a rare event, suicide is undoubtedly one the most feared outcomes when any patient absconds. Preventing harm to self or others is often the main rationale for in-patient admission. It is also a ubiquitous criterion for involuntary admission. Consequently, preventing harm is one of the main motives for locking psychiatric units.

In our study, $86 \%$ of unauthorised absences over the 1 -year study period were by involuntarily admitted patients. In opening our doors, are we doing these individuals a disservice by giving them the opportunity to leave hospital at a time when they are most unwell?

Previous studies have reported on the negative consequences of absconding for patients (interrupted treatment, suicide), staff (anxiety), family members (loss of trust in the service), and emergency services (expended resources). ${ }^{3}$ It could be argued that a reduction in the number of violent incidents (and, in Beaglehole's case, seclusion) is worth the risk of these adverse outcomes. In our view, however, a modern purpose-built environment coupled with increased staffing levels better explains these findings. Increased numbers of nursing staff result in improved relational security, an important element of therapeutic security provided by higher staff-to-patient ratios. ${ }^{4}$

Our study and that of Beaglehole and colleagues indicate that unlocking acute psychiatric wards leads to an upsurge in unauthorised absences. The majority of patients who absconded were admitted involuntarily. We suggest that acute mental health services give careful consideration to all the risks associated with unauthorised absences before opening their 
doors. This is of particular relevance given that rates of involuntary admission are on the rise. ${ }^{5}$

Damian Smith, Senior Registrar in General Adult Psychiatry and Clinical Tutor, and MacDara McCauley, Consultant Psychiatrist and Clinical Lecturer, Louth Meath Mental Health Services and Royal College of Surgeons Ireland; email: damiansmith@rcsi.com

1 Beaglehole B, Beveridge J, Campbell-Trotter W, Frampton C. Unlocking an acute psychiatric ward: the impact on unauthorised absences, assaults and seclusions. BJPsych Bull 2017; 41: 92-6.

2 Huber CG, Schneeberger AR, Kowalinski E, Fröhlich D, Felten von S, Walter $M$, et al. Suicide risk and absconding in psychiatric hospitals with and without open door policies: a 15 year, observational study. Lancet Psychiatry 2016; 3: 842-9.
3 Bailey J, Page B, Ndimande N, Connell J, Vincent C. Absconding: reducing failure to return in adult mental health wards. BMJ Qual Improv Rep 2016; 5: u209837.w5117.

4 Kennedy HG. Therapeutic uses of security: mapping forensic mental health services by stratifying risk. Adv Psychiatr Treat 2002; 8: 433-43.

5 Gilhooley J, Kelly BD. Return of the asylum. Br J Psychiatry 2018; 212 69-70.

doi:10.1192/bjb.2018.35

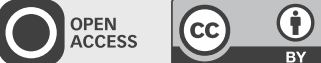

(c) The Authors 2018. This is an Open Access article, distributed under the terms of the Creative Commons Attribution licence (http://creativecommons.org/ licenses/by/4.0/), which permits unrestricted re-use, distribution, and reproduction in any medium, provided the original work is properly cited. 